\title{
Electroencephalographic Studies on Liquefied Petroleum Gas Poisoning in Rabbits
}

\author{
Setsuo Komura, ${ }^{*}$ Masao Ueda and Kazuaki Fujmura* \\ Department of Legal Medicine, School of Medicine, Kyoto \\ University, Kyoto
}

Komura, S., UEdA, M. and FojIMURA, K. Electroencephalographic Studies on Liquefied Petroleum Gas Poisoning in Rabbits. Tohoku J. exp. Med., 1973, 111 (1), 33-40 Rabbits were put into a special box which had a gas-exit and an upperpositioned gas-inlet, from which the Japanese Industrial Standard No. 3 Liquefied Petroleum Gas (L.P.G.) was distributed on equal proportion. The changes in the behavior were noted as follows: Initially, licking and sniffing appeared, and at about one hour later when the L.P.G. concentration reached approximately $30 \%$, the walking got difficult, and occasional screaming were heard as the sign of stimulation. At about 100 minutes later, namely at approximately 60\% L.P.G. concentration, temporary nystagmus appeared. After that, the muscles were hypotonic, and an excessive salivation was noted. The E.C.G. changes were as follows: With the initial sending in of L.P.G., the pulse rate increased gradually until about the 2 hours' peak-point after which it decreased again being accompanied with $\mathrm{S}-\mathrm{T}$ depression and inverted $\mathrm{T}$ wave, clearly indicating the presence of some cardiac damage. The neocortex showed a gradual change into a drowsy pattern, while the hippocampus and amygdala showed a marked arousal pattern. Especially the amygdala evoked many preseizure and seizure-spikes, and other amygdala-related locations like the anterior hypothalamus showed a similar tendency. At 2 hours of experiment, both the activation effect of the reticular formation over the neocortex and the recruiting response of $\mathrm{N}$. centrum medianum of thalamus showed a marked elevation of threshold. At this stage, the seizure discharge due to the electric stimulation of hippocampus or amygdala showed only a slight decrease of amplitude but the duration remained almost unchanged.- liquefied petroleum gas; poisoning; electroencephalography; electrocardiography

Liquefied petroleum gas (L.P.G.), as fuel, recently has become very popular for room-heating, home-cooking and fuel for motor cars. On the other hand, cases of the intoxication due to noxious gases produced during its burning and chances of suffering from L.P.G. poisoning have increased remarkably in Japan. In fact, several cases of L.P.G. poisoning have been reported (Papp 1959; Shikata et al. 1961; Tolnay 1963; Fukita and Sugimoto 1965; Nagata et al. 1971). However, little is known about the effect of L.P.G. upon a living body and almost no electrophysiological studies have been made about it.

Received for publication, February 6, 1973.

* Present Address: Department of Legal Medicine, Yamaguchi University School of Medicine, Ube-755, Japan. 
In the field of brain physiology, the concept of the reticular activating system was reported (Moruzzi and Magoun 1949). The diffuse thalamic projection system was reported (Jasper 1949) and also studies of the limbic system have made progress. On the bases of these concepts many problems in this field were clarified or solved. The authors, considering the recent trends in this field, conducted an electrophysiological experiment to clarify the effect of L.P.G. on the central nervous systems. This was done by observing the behavior, E.E.G. and E.C.G. of rabbits implanted with subcortical and cortical electrodes.

\section{Materials and Methods}

Experiments were performed on 20 male rabbits weighing $2.8-3.3 \mathrm{~kg}$.

During the procedure of implanting the electrodes into the brain, the rabbit was anesthetized with nembutal and the head was fixed to the Todai Type Stereotaxic Instrument. After the surface of the skull was exposed, drill holes were opened in the skull. In general, 4 concentric needle type subcortical electrodes and 2 silver-ball cerebral cortex electrodes for a rabbit were placed stereotaxically through the holes in the skull, according to the atlas of Sawyer et al. (1954). The positions of cortical and subcortical electrodes were as follows: cortex limbicus at posterior $(\mathrm{P})$ 11, lateral $(\mathrm{L}) 2.5$; cortex sensitivo-motorius anterior at (A) 4, L3; anterior hypothalamic area at Al, L1.5, height $(\mathrm{H})-2.5$; amygdala at $\mathrm{A} 3, \mathrm{~L} 6.5, \mathrm{H}-5.5$; hippocampus $\mathrm{P} 4, \mathrm{~L} 3, \mathrm{H} 4.5$; $\mathrm{N}$. centrum medianum of the thalamus at $\mathrm{P} 5, \mathrm{~L} 2, \mathrm{H}-1$; posterior hypothalamic area at $\mathrm{P1}, \mathrm{Ll} .5, \mathrm{H}-3$ and reticular formation at P8, L2.5, H-2.

A subcortical concentric electrode consists of both an outer steel tube (its caliber: $100 \mu$, the length from $5 \mathrm{~mm}$ to $22 \mathrm{~mm}$ according to the depth to which it was inserted) and an inner insulated wire incased in the outer steel tube. The surfaces of the inner and outer electrodes were coated with "Kashu", a kind of varnish, and the tip of the inner electrode was cut at $1 \mathrm{~mm}$ from the outer electrode. The insulating "Kashu" was rubbed off $0.5 \mathrm{~mm}$ in width from the tip of the inner electrode and from an area $0.5 \mathrm{~mm}$ above the outer electrode tip. A cortical electrode was made from a silver wire with a silver ball (diameter $1.0 \mathrm{~mm}$ ) at the end of it. This was coated with "Kashu" except for its tip. Bipolar leads were used and the electrodes were placed $3 \mathrm{~mm}$ apart on the dura mater. All the implanted electrodes were fixed to the skull with sticky wax and connected with a socket through lead wires. The socket and 2 screw nails, already fixed to the skull, were consolidated together with a dental cement "Poly Set".

After a certain period, ( 2 weeks or so) of recuperation, the rabbits were used for experiments. Rabbits were placed in a chamber for the experiment where the E.E.G. and E.C.G. (leads I, II and III) recordings could be taken in non-anesthetic and unrestrained conditions. The chamber (the size: $80 \times 80 \times 160 \mathrm{~cm}$ ) was air-tight and had a ventilation tube on the top of it (Komura 1967). Through this tube JIS-NO 3 LPG gas was insufflated slowly, so that the gas was distributed in equal proportions during experiments. This chamber was designed so that the internal materials and/or rabbits could be handled from the outside through air-tight rubber gloves fixed to this chamber.

For the recording of E.E.G. and E.C.G. a polygraph, RM-150, Nihonkoden, was used. Electrical stimulations were made with the Stimulator, MSF-3, Nihonkoden, through the implanted electrodes. We studied the effects of seizure discharges in the neocortex, hippocampus and amygdala after stimulating each area with high frequency stimulation $(300$ c.p.s., 0.5 msec duration and $5 \mathrm{sec}$ ), and the effects of arousal responses produced by high frequency stimulation of the midbrain reticular formation, the anterior hypothalamic area and the posterior hypothalamic area, and the effect of recruiting response produced by the low frequency stimulation (8 c.p.s., 1 msec duration and 5 sec) of the $\mathrm{N}$. centrum medianum of the thalamus. After the experiments their brains were fixed in $10 \%$ formalin for subsequent histological examinations. 
The concentration of L.P.G. in this gas chamber was measured by Shimazu GC-2B gas chromatography equipped with Model HFD-I dual hydrogen flame ionization detector (Inamoto et al. 1966). The oxygen concentration was measured by Kitagawa's gas detector and detecting tubes, made by Komyo Rikagaku.

\section{Results}

\section{L.P.G. concentration in the specially designed gas chamber}

The L.P.G. used is the one commercially sold, designated as Japanese Industrial Standard (JIS) NO 3, and contained in $10 \mathrm{Kg}$-home-sized tanks. The ratio of constituents of L.P.G. differs at the beginning and the end of gas emission from a tank; the relative amount of propane decreases while that of $n$-butane increases gradually. So, the first one third of the gas in the tank was used. The typical constituents of L.P.G. at 60 minutes after the onset of L.P.G. insufflation are as follows: ethane 5.3, propane 49.9, n.butane 11.2, propylene 27.5 and iso-butane $4.3 \%$. The L.P.G. concentration in the gas chamber was about $30 \%$ of the air at 60 minutes after the onset of L.P.G. insufflation and about $70 \%$ of the air at 120 minutes. The oxygen concentration in this chamber was about $10 \%$ at 110 minutes after the insufflation of L.P.G. At this degree of $\mathrm{O}_{2}$ depletion, no E.E.G. change could be found, even when the period of experiment was to 120 minutes.

\section{Behaviors of the rabbits and their E.C.G. and E.E.G.}

The animals used were 20 male rabbits, 5 months of age. Before L.P.G. insufflation, the heads were in normal positions and with ears straightened. At the time, a typical rabbit showed pulse rate of $294 / \mathrm{min}$ and respiratory frequency of 72/min. While L.P.G. was slowly insufflated the rabbit was licking, smacking, sniffing, jumping up occasionally and walking around. When the L.P.G. concentration reached up to $35 \%$, the walking gradually became difficult and the rabbits occasionally squeaked in excitement. The pulse rate and respiratory frequency increased to $336 / \mathrm{min}$ and $101 / \mathrm{min}$ respectively and the E.C.G. showed arrhythmia with extrasystole. When the L.P.G. concentration reached $60 \%$, nystagmus appeared. When the concentration came to $70 \%$ at 120 minutes after the start of insufflation, nystagmus became somewhat less, salivation became prominent and muscle became weakened. Pulse rate and respiratory frequency decreased to 240/min and 65/min, respectively. E.C.G. showed a depression of ST and an inversion of $\mathrm{T}$, suggesting myocardial damage.

At the same time, the E.E.G. change of the same rabbits was recorded with persistent electrodes. At first when L.P.G. insufflation started, the neocortical E.E.G. showed occasionally a fast wave. As the concentration of L.P.G. increased, the E.E.G. showed a gradual change into a drowsy pattern. On the other hand, the E.E.G. of hippocampus and amygdala, which belong to the limbic system, came to show fast and regular waves, showing an arousal pattern in contrast to the neocortical changes. At 120 minutes after the L.P.G. insufflation, the amygdaloid E.E.G. showed spontaneous preseizure spikes or seizure spikes. The 
anterior hypothalamus showed a similar tendency, as shown in Fig. 1, 2, and 3. Hereafter, as the gas concentration increased still more, E.E.G. of both amygdala and hippocampus gradually came to show drowsy patterns. When L.P.G. was released from the chamber, every E.E.G. rapidly returned to arousal patterns. These results show that there is a period, which has clearly a kind of dissociation between neocortical E.E.G. and hippocampal and amygdaloid E.E.G..

\section{EEG Patterns}



Amg

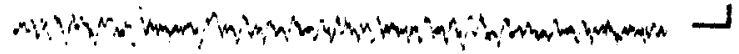

Aha

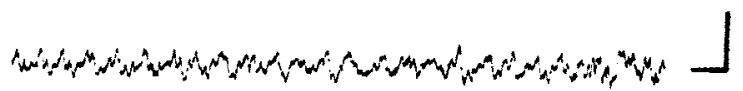

Fig. 1. E.E.G. patterns of the hippocampus, the amygdala and the anterior hypothalamic area before L.P.G. inhalation.

Hpc, hippocampus: Amg, amygdala; Aha, anterior hypothalamic area.

EEG Patterns

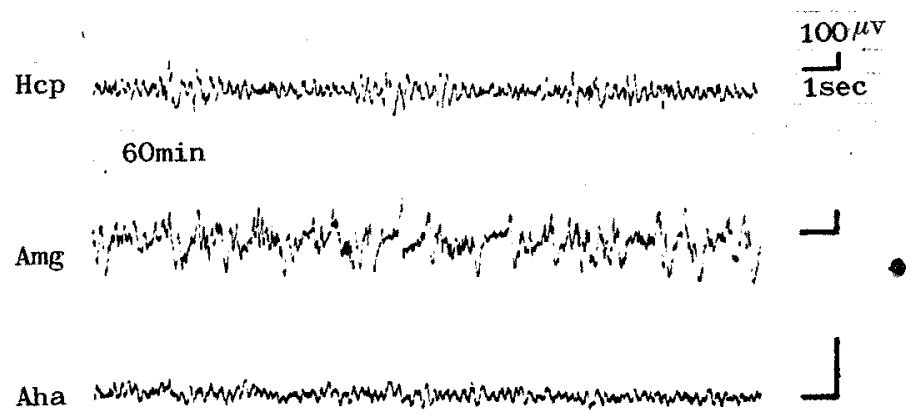

Fig. 2. E.E.G. patterns of the hippocampus, the amygdala and the anterior hypothalamic area at 60 minutes of L.P.G. inhalation. 
EEG Patterns

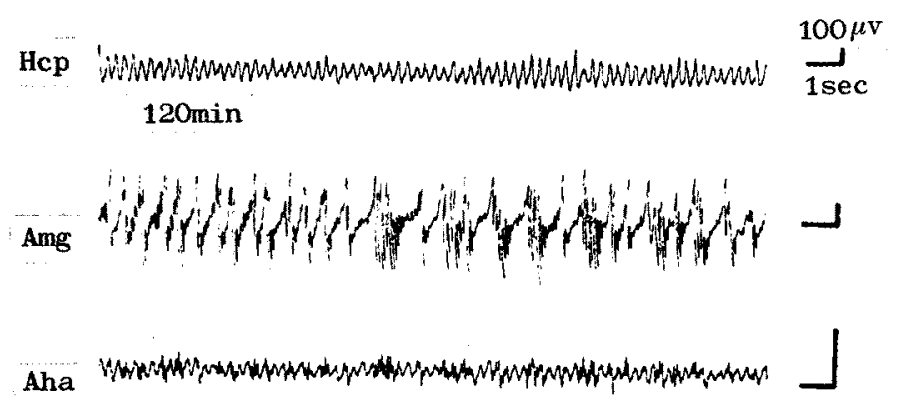

Fig. 3. E.E.G. patterns of the hippocampus, the amygdala and the anterior hypothalamic area at 120 minutes of L.P.G. inhalation.

\section{Seizure discharges}

In order to ascertain the result mentioned above, the authors studied the degree of functional disturbances in the neocortex, hippocampus and amygdala, by observing the seizure discharge after stimulating each area with high frequency stimulation (Kaada 1951; Miyasaka and Kawamura 1963; Komura 1967). While a marked depression was observed in the seizure discharge of the neocortex following stimulation at 120 minutes after the start of L.P.G. insufflation, the seizure discharges from hippocampus and amygdala showed only a slight decrease of amplitude but the duration remained almost unchanged. These observations suggested that, in this stage of L.P.G. intoxication, the neocortex received an inhibitory effect while the hippocampus and amygdala received facilitating effects. As amygdala showed preseizure or seizure spikes spontaneously without external stimuli while hippocampus showed these spikes only after stimulation, amygdala seemed to get stronger facilitating effects than hippocampus.

\section{On various activating systems}

The results mentioned above showed that L.P.G. acted differently on the different area of the brain. Then we studied the action of L.P.G. at 120 minutes of gas insufflation, on the ascending reticular activating system, the diffuse thalamic projection system and the hypothalamic activating system (Tokizane et al. 1960). The results were as follows: the threshold elevations of reticular arousal response (Fig. 4) and recruiting response were $88.8 \pm 8.3 \%$ (4) and $82.0 \pm 10.4 \%$ (4) (means \pm S.D., number of the rabbits in brackets), respectively, and the hypothalamic activating system showed no threshold elevation or a threshold depression and 




Fig. 4. E.E.G. arousal response of the neocortex induced by the stimulation of the midbrain reticular formation before and during L.P.G. inhalation. The bars indicate the duration of the stimulus. $\mathrm{Cm}$, cortex sensitivo-motorius; $\mathrm{Cl}$, cortex limbicus.

appeared to be in a state of hyperfunction. The hyperfunction seemed to suggest a facilitating effect on this system or hypofunction of some other system, which might act inhibitory against this system in normal state.

It now appears established that the ascending reticular activating system is concerned with consciousness (Moruzzi and Magoun, 1949) and recruiting responses, which are induced in the neocortex by the low frequency stimulation of the medial nucleus of the thalamus, also are closely concerned with consciousness (Verzeano et al. 1953). The marked hypofunction of the systems, which were observed in this experiment, suggests a strong disturbance of consciousness. At the same time, the hyperfunction of the hypothalamic activating system, especially of the anterior hypothalamus and the amygdala, was observed.

\section{Discussion}

Wolf and Menne (1937) observed a decrease of blood pressure, bradycardia, arrhythmia and an increase of pulse-pressure in their experiment, with a $50 \%$ concentration of "Propanflüssiggas". These symptoms improved or disappeared after the blocking of the both-sided vagal nerves or upon the administration of large amount of atropin. In their experiments with rats, the animals became excitatory or anesthetized as the gas concentration increased, and at the recovering stage spasm and hypersalivation appeared.

There are many similarities between their findings and ours. In our experiments, as the animals were recovering from their intoxicated state, the E.E.G. from each area rapidly changed to arousal patterns and in the amygdaloid or anterior hypothalamic E.E.G. preseizure or seizure spikes were sometimes observ- 
ed. The fast waves indicate arousal or excited states, and seizure spikes in amygdala suggest the excitation of the parasympathetic system, which accelerates salivation. These results seem to explain the phenomena observed by Wolf and Menne (1937).

Shikata et al. (1961) observing rats exposed to L.P.G. reported that the gas had anesthetic actions and caused motor disturbances. We found with L.P.G. intoxication the marked hypofunctions of the ascending reticular activating system and of the diffuse thalamic projection system, which are profoundly implicated in the maintenance of the conscious state (Moruzzi and Magoun 1949, Verzeano et al. 1953). As for the cortical E.E.G. in animals, Inamoto et al. (1966) reported that prominent slow waves appeared in L.P.G. intoxication. This seems to be the only other report on this subject besides ours that is similar to theirs.

According to the experiments of Matsumoto and Yoshida (1965), the lethal dose of L.P.G. concentration for rats or rabbits is between 65 and $68 \%$ and the anesthetic dose is between 40 and $50 \%$. These values did not appreciably change when a hypoxic state was avoided. Our results support their observations.

As to the arrhythmia in our experiments, Wolf and Menne (1937) also reported similar findings. The extrasystole in our experiments is said to appear also in propylene gas intoxication (Sollmann 1957). We observed the depression of ST and the inversion of T on E.C.G. We are not aware of any studies that observed the occurrence of these. The findings on ST and $\mathrm{T}$ suggest the occurrence of some degree of myocardial damage.

Based on the results mentioned above, in the case of L.P.G. intoxication, there was certainly a cardiac damage as well as the stimulation of anterior hypothalamus and amygdala. The function of some other area which acts inhibitory against hypothalamus and amygdala might have been depressed. It is also important that the authors could confirm that both the ascending reticular activating system and the diffuse thalamic projection system suffered marked hypofunction.

\section{References}

1) Fukita, K. \& Sugimoto, M. (1965) The influence of fuel propane gas on living body (III) changes of blood cells. Jap. J. leg. Med. (Jap.), 19, 461.

2) Inamoto, A., Okuda, Y. \& Niou, K. (1966) Analysis of liquefied petroleum gas and the influence on living body (I). Jap. J. Anesth. (Jap.), 15, 570.

3) Jasper, H. (1949) Diffuse projection systems: the integrative action of the thalamic reticular system. Electroenceph. clin. Neurophysiol., 1, 405-419.

4) Kaada, B.R. (1951) Somato-motor, autonomic and electrocorticographic responses to electrical stimulation of rhinencephalic and other structures in primates, cat and dog. Acta physiol. scand., 24, Supple. 83, 1-285.

5) Komura, S. (1967) Electroencephalographic studies on carbon monoxide poisoning in rabbits. Jap. J. leg. Med. (Jap.), 21, 25-48.

6) Matsumoto, H. \& Yoshida, Y. (1965) The experimental study on the properties of liquefied petroleum gas. Jap. J. leg. Med. (Jap.), 19, 244.

7) Miyasaka, M. \& Kawamura, H. (1963) Effect of reticular and hypothalamic stimulation upon the susceptibility of the neocortex, amygdala and hippocampus to seizure 
discharges. Folia psychiat. neurol. jap., 17, 230-242.

8) Moruzzi, G. \& Magoun, H.W. (1949) Brain stem reticular formation and activation of the EEG. Electroenceph. clin. Neurophysiol., 1, 455-473.

9) Nagata, T., Kojima, T. \& Makisumi, S. (1971) Quantitative gas chromatographic determination of propane and liquefied petroleum gas in biological materials. Jap. J. leg. Med. (Jap.), 25, 439-444.

10) Papp, A. (1959) Fälle von Propan-Butan-Gas-Vergiftungen. Münch. med. Wschr., 101, 235-237.

11) Sawyer, C.H., Everett, J.W. \& Green, J.D. (1954) The rabbit diencephalon in stereotaxic coordinates. J. comp. Neurol., 101, 801-824.

12) Shikata, I., Maeiwa, M., Hata, R., Shinomiya, T. \& Orino, K. (1961) A case of poisoning by fuel propane gas. Shikoku Acta med. (Jap.), 17, 93-96.

13) Sollmann, T. (1957) A Manual of Pharmacology and Its Applications to Therapeutics and Toxicology. 8th. ed., Saunders, Philadelphia \& London, p. 913.

14) Tokizane, T., Kawamura, H. \& Imamura, G. (1960) Hypothalamic activation upon electrical activities of paleo-and archicortex. Neurol. medico-chirurgica, 2, 63-76.

15) Tolnay, L. (1963) Ein kombinierter Selbstmord durch reine Asphyxie mit einem über den Kopf gestülpten Nylonsack. Arch. Krim., 132, 42-46.

16) Verzeano, M., Lindsley, D.B. \& Magoun, H.W. (1953) Nature of recruiting response. $J$. Neurophysiol., 16, 183-195.

17) Wolf, H.J. \& Menne, F. (1937) Akute Vergiftung durch einen neuem Motortreibstoff (Propanflüssiggas). Naunyn-Schmiedeberg's Arch. exp. Path. Pharmak., 186, 7888. 